Check for updates

Cite this: RSC Adv., 2018, 8, 42280

\title{
Coconut-based activated carbon fibers for efficient adsorption of various organic dyes
}

\author{
Ling Zhang, (D) ab Ling-yu Tu, ${ }^{\mathrm{b}}$ Yan Liang, ${ }^{\mathrm{a}}$ Qi Chen, (D) ${ }^{\mathrm{b}}$ Ze-sheng Li, (D) ${ }^{\mathrm{b}}$ \\ Chun-hai Li, *ab Zhi-hui Wang ${ }^{a}$ and Wen Lib
}

In this study, using coconut fibers as raw material, activated carbon fibers were prepared via carbonization and $\mathrm{KOH}$ activation processes. The morphology, composition, specific surface area, pore structure and thermal stability of the resulting activated carbon fibers were systematically characterized. It was found that the activation process increases the specific surface area of carbon fibers to a greater extent via formation of a large number of micropores $(0.7-1.8 \mathrm{~nm})$ and a certain amount of slit-shaped mesopores (2-9 nm). The specific surface area and the pore volume of the activated carbon fibers reach $1556 \mathrm{~m}^{2}$ $\mathrm{g}^{-1}$ and $0.72 \mathrm{~cm}^{3} \mathrm{~g}^{-1}$, respectively. The activation process can also decompose the tar deposits formed after the carbonization process by pyrolysis, making the surface of the activated carbon fibers smoother. To study the adsorption properties of the as-prepared activated carbon fibers, the adsorption capacities and adsorption kinetics of various organic dyes including methylene blue, Congo red and neutral red were investigated. The adsorption capacities of the dyes increased with the increasing initial dye concentrations, and varied greatly with the $\mathrm{pH}$ value of the system. In methylene blue and neutral red systems, the adsorption capacities reach the maximum at $\mathrm{pH}$ 9, and in the Congo red system, it reaches the maximum at $\mathrm{pH}$ 3. The adsorption capacities of the activated carbon fibers in methylene blue, Congo red and neutral red systems reached equilibrium at 150,120, and $120 \mathrm{~min}$, and the maximum adsorption capacities were 21.3, 22.1, and $20.7 \mathrm{mg} \mathrm{g}^{-1}$, respectively. The kinetics of the adsorption process was investigated using three models including pseudo-first-order, pseudo-second-order and intraparticle diffusion models. The results indicated that the dynamic adsorption processes of coconutbased activated carbon fibers to methylene blue, Congo red and neutral red were all in accordance with the second-order kinetic model, and the equations are as follows: $t / Q_{t}=0.1028+t / 21.3220, t / Q_{t}=$ $0.1128+t / 21.5982$ and $t / Q_{t}=0.0210+t / 20.6612$.

Received 30th October 2018 Accepted 24th November 2018

DOI: $10.1039 / \mathrm{c} 8 \mathrm{ra0} 08990 \mathrm{f}$

rsc.li/rsc-advances polyimide, etc.), lignins and natural plant fibers (e.g. hemp, flax, coconut, etc. $).^{5-7}$ With regard to the preparation method, activated carbon fibers can be obtained by physical activation (disordered carbon atoms in fibrous materials are oxidized to form pores by etching effect with oxygen, carbon dioxide and water vapor as activators ${ }^{\mathbf{8 - 1 0}}$ ), chemical activation (the pore structure is formed via chemical reactions between carbon atoms and phosphoric acid, potassium hydroxide, zinc chloride, or ammonium sulfate ${ }^{\mathbf{1 1 - 1 3}}$ ) and physical-chemical complex activation processes (the physical and chemical activation methods are combined to achieve a complementarity in the aspect of pore structure regulation and prime cost manipulation ${ }^{\mathbf{1 4}}$ ).

With ever-increasing concerns on environmental pollutions and energy crisis, the feedstock of activated carbon fibers has gradually turned from petroleum resources to biomass-based materials. ${ }^{15,16}$ Biomass is a promising feedstock for the preparation of activated carbon fibers because of its abundance, environmental friendliness, low cost and good renewability. In addition, using biomass as a feedstock also affords a facile route
${ }^{a}$ Technology for Lingnan Characteristic Fruits \& Vegetables Processing and Application Engineering of Guangdong Province, Food Science Innovation Team of Guangdong Higher Education Institutes, Guangdong University of Petrochemical Technology, Maoming 525000, Guangdong, China. E-mail: mmzhl1130@gdupt.edu.cn; gdmm0808@126.com

${ }^{b}$ College of Environmental and Biological Engineering, Guangdong University of Petrochemical Technology, Maoming 525000, Guangdong, China 
to tailor the pore structures of the activated carbon fibers. ${ }^{\mathbf{1 7 - 1 9}}$ Coconut fiber is a natural filamentous material extracted from coconut shell, which can be used as ropes, brushes, cushions, mattress and fiber filter due to its abundance, non-toxic nature and good mechanical properties. ${ }^{\mathbf{2 0 - 2 2}}$ In spite of numerous scientific, technological and economic benefits, coconut fibers are unfortunately scarcely utilized in developing countries. Only a small portion of coconut fibers is utilized and most of them are discarded or burnt as fuel. ${ }^{23,24}$ A large amount of coconut fibers are discarded every year as wastes, which has caused a serious waste of resources. Therefore, if the coconut fiber and its product wastes are transferred into activated carbon fibers, the added-value of these materials can be greatly improved.

In this study, high-performance activated carbon fibers with a high micropore volume and large specific surface area have been prepared using coconut fiber as a precursor via hightemperature carbonization and $\mathrm{KOH}$ activation processes. The as-prepared activated carbon fiber was characterized by scanning electron microscopy (SEM), XPS, $\mathrm{N}_{2}$ adsorption-desorption isotherms, and thermogravimetric analysis. The adsorption properties of the activated carbon fiber for various dyes including methylene blue, Congo red and neutral red were further studied. The effects of initial concentration of dye pollutants, solution $\mathrm{pH}$ and contact time on the adsorption performance were investigated.

\section{Experimental section}

\subsection{Material and reagents}

Coconut fiber was provided by Zhaokuo Purification Equipment Co., Ltd., Shanghai, China. Other chemical reagents were of analytical grade and used as received without further purification.

\subsection{Preparation of activated carbon fibers from coconut fibers}

The carbonization of coconut fibers was first conducted under $600{ }^{\circ} \mathrm{C}$ using a box-type resistance furnace. The sample was placed in a covered ceramic crucible filled with other activated carbon to form an oxygen-free environment. Herein, $10 \mathrm{~g}$ of the carbonized coconut palm was mixed with $20 \mathrm{~g}$ of $\mathrm{KOH}$ ethanoic solution. The mixture was heated and stirred using a heatingmagnetic mixer until ethanol was completely evaporated. The dried mixture was placed in a vacuum tube furnace and heated at $900{ }^{\circ} \mathrm{C}$ in a nitrogen protection environment for $150 \mathrm{~min}$. The obtained crude product was soaked and rinsed with distilled water for several times and then dried to obtain the coconut fiber-based activated carbon fibers.

\subsection{Structural characterization}

The microstructure and chemical composition of activated carbon fibers were observed by Quanta 200 scanning electron microscopy (SEM) from Holland FEI Company. Elemental chemical statuses of the prepared samples were observed by KAlpha $^{+}$X-ray Photoelectron Spectroscopy (XPS) from Thermo fisher Scientific. The external surface morphology and defects of activated carbon before and after activation were observed and analyzed at different magnifications. The $\mathrm{N}_{2}$ adsorptiondesorption isotherms were recorded using a JW-BK100A specific surface area and pore size analyzer (Beijing JWGB SCI \& Tech Co. Ltd) at $77 \mathrm{~K}$. Activated carbon fibers were dried at $300{ }^{\circ} \mathrm{C}$ in vacuum for $160 \mathrm{~min}$ before analyses. The specific surface area of the sample was determined by the Brunauer-Emmett-Teller and Langmuir methods. The distribution of mesopores was analyzed by the Barrett-Joyner-Halenda method, while that of micropores was analyzed by the $t$-plot and Horvath-Kawazoe methods. The TGA analyses of the samples were recorded using a STA449F3 synchronous thermal analyzer from NETZSCH Company, Germany. The temperature range is from 25 to $1100{ }^{\circ} \mathrm{C}$ and the heating rate is $10 \mathrm{~K} \mathrm{~min}^{-1}$. High-purity nitrogen

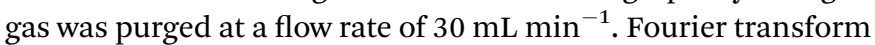
infrared (FTIR) spectra were recorded using a VERTEX 70 Fourier transform infrared spectrometer. The activated carbon fibers and $\mathrm{KBr}$ were mixed and then compressed into tablets. The FTIR analysis was conducted at a wavelength range of 400$4000 \mathrm{~cm}^{-1}$.

\subsection{Study on adsorption properties of activated carbon fibers}

The adsorption of three kinds of dye solutions, namely methylene blue, Congo red, and neutral red dye was investigated. Typically, $10 \mathrm{mg}$ of activated carbon fibers were first added into $50 \mathrm{~mL}$ of dye solutions with varying initial concentrations. The $\mathrm{pH}$ of the mixture was adjusted to a fixed value. The variation in dye concentration was monitored using a $722 \mathrm{G}$ visible spectrophotometer. The effects of initial dye concentration, solution $\mathrm{pH}$ and contact time on the adsorption performance were investigated. The adsorption capacity $\left(Q_{\mathrm{e}}\right)$ was calculated using eqn $(1):^{25}$

$$
Q_{\mathrm{e}}=\left(C_{0}-C_{\mathrm{e}}\right) \times V / m
$$

where $C_{0}\left(\mathrm{mg} \mathrm{L}^{-1}\right)$ is the initial concentration of dye solution, $C_{\mathrm{e}}$ $\left(\mathrm{mg} \mathrm{L}^{-1}\right)$ is the residual concentration of dye solution, $V(\mathrm{~L})$ is the volume of dye solution, and $m(\mathrm{~g})$ is the mass of activated carbon fibers. The adsorption rate was determined using eqn (2):

$$
D=\left(C_{0}-C_{\mathrm{e}}\right) / C_{0} \times 100 \%
$$

In order to analyze the adsorption kinetics, three kinds of adsorption kinetics models including pseudo-first-order equation, pseudo-second-order equation, and intraparticle diffusion equation were applied as shown in eqn (3)-(5): ${ }^{26}$

$$
\text { Pseudo-first-order equation: } \ln \left(Q_{\mathrm{e}}-Q_{t}\right)=\ln Q_{\mathrm{e}}-K_{1} t
$$

where $Q_{t}$ is the adsorption capacity at time $t(\mathrm{~min}), Q_{\mathrm{e}}\left(\mathrm{mg} \mathrm{g}^{-1}\right)$ is the equilibrium adsorption capacity, and $K_{1}$ is the constant of quasi-first-order equation.

$$
\text { Pseudo-second-order equation: } t / Q_{t}=1 /\left(K_{2} Q_{\mathrm{e}}{ }^{2}\right)+t / Q_{\mathrm{e}}
$$

where $K_{2}$ is the constant of quasi-second-order equation. 


$$
\text { Intraparticle diffusion equation: } Q_{t}=K_{\mathrm{p}} t^{1 / 2}+C
$$

where $K_{\mathrm{p}}$ is the constant of particle diffusion constant and $C$ is the experimental constant.

\section{Results and discussion}

\subsection{Microstructure and chemical composition of the carbon} fibers

From the SEM images shown in Fig. $1 \mathrm{a}_{1}-\mathrm{a}_{3}$, it can be observed that the carbonized coconut fiber presents a filamentous morphology with strip axial arrangement, and that a few longitudinal grooves and many irregular particles are distributed on the fiber surface. The SEM images shown in Fig. $1 b_{1}-b_{3}$ reveal that the surface of activated carbon fiber is smoother after activation. More holes and pits are noted. Some axial wedge fractures are also observed because of high-temperature pyrolysis and activation, but the longitudinal texture and porosity of coconut biochar are still retained. It is concluded that the particles on carbonized coconut fiber are carbon species formed from the pyrolysis oil. ${ }^{27}$ In the activation process, $\mathrm{KOH}$ can corrode the surface carbon species and result in the formation of numerous micropores and large specific surface areas under high temperatures. ${ }^{28}$

In order to analyze the changes in the elemental components before and after activation of carbon fibers, the EDS spectra of point I and point II were analyzed, respectively. The results shown in Fig. 2 indicate that carbon fibers before and after activation all contained different contents of carbon, oxygen and potassium elements. The carbonated coconut fibers still retained high levels of oxygen and potassium because the raw material itself contained these two elements. However, the contents of the two elements decreased after activation, which may be due to the partial decomposition of oxygen by secondary high-temperature treatment during activation, and the dissolution and loss of potassium during washing.

\subsection{XPS analysis}

The chemical compositions of carbonized coconut fibers and activated carbon fibers were further analyzed by XPS, and the results are shown in Fig. 3. The C1s XPS spectra of the two
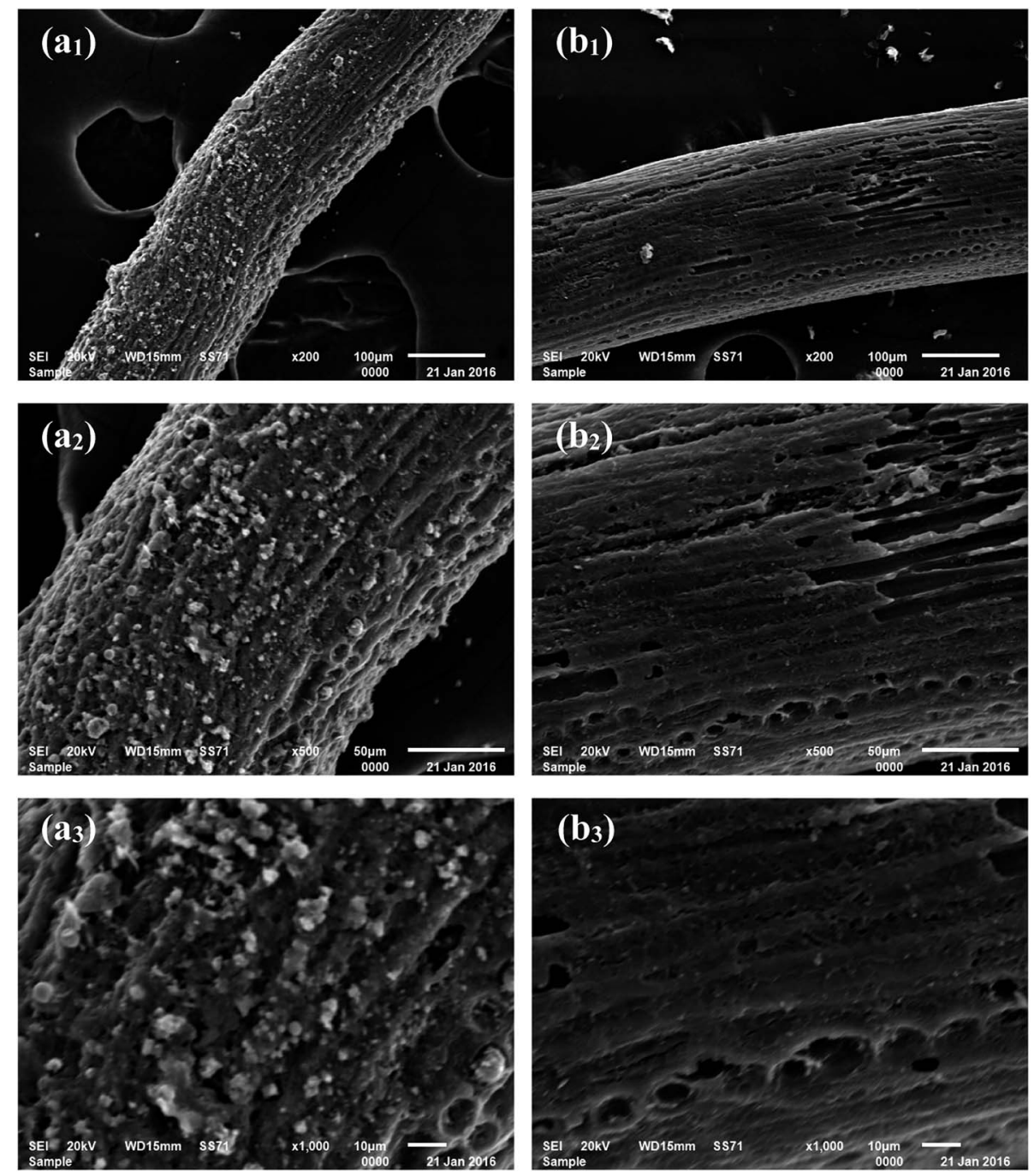

Fig. 1 SEM images of carbonized coconut fibers $\left(a_{1}-a_{3}\right)$ and activated carbon fibers $\left(b_{1}-b_{3}\right)$ at different magnifications. 

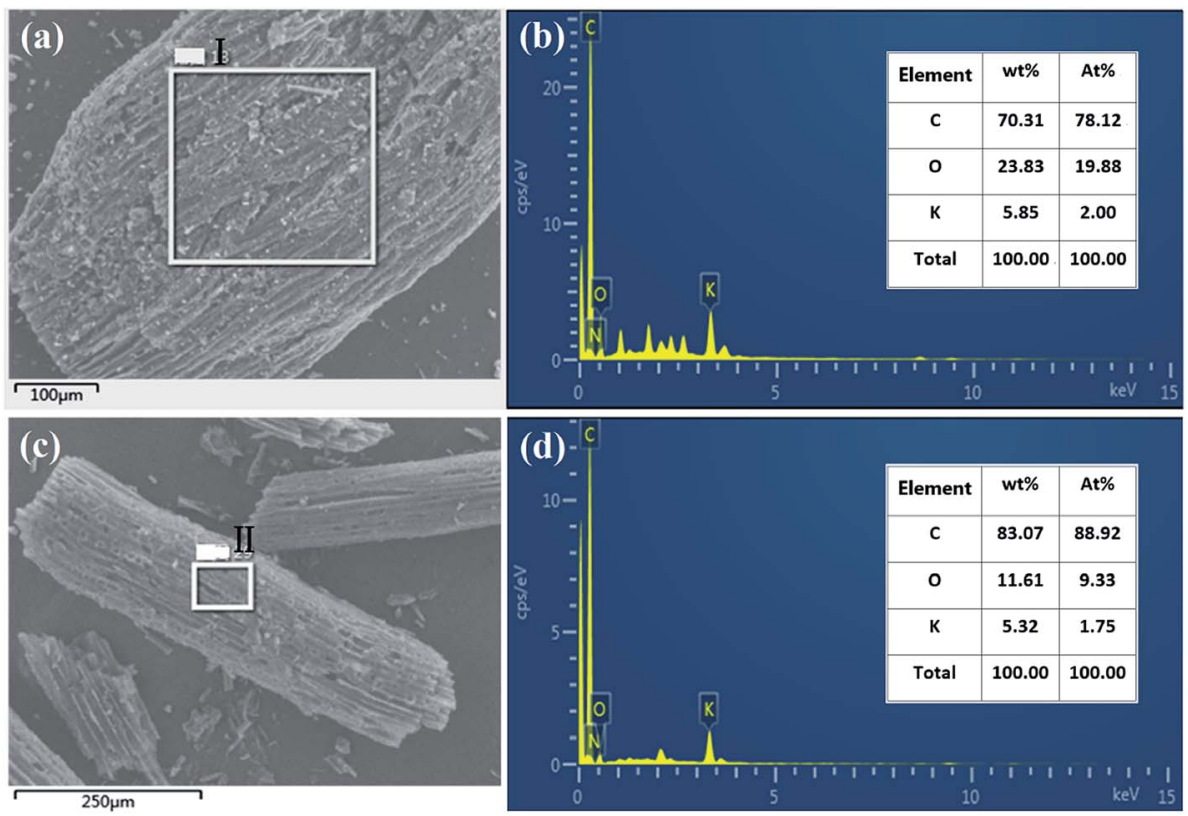

Fig. 2 EDS spectrum of carbonized coconut fibers ( $a$ and $b$ ) and activated carbon fibers ( $c$ and d).

samples (Fig. 3a and b) exhibited three main peaks with binding energies of around 289, 286 and $285 \mathrm{eV}$, which correspond to the functional groups of $\mathrm{O}-\mathrm{C}=\mathrm{O}, \mathrm{C}-\mathrm{O}$ and $\mathrm{C}-\mathrm{C}$, respectively. ${ }^{29}$ For carbonized coconut fibers, the proportions of $\mathrm{O}-\mathrm{C}=\mathrm{O}, \mathrm{C}-\mathrm{O}$ and $\mathrm{C}-\mathrm{C}$ are $14.5 \%, 19.2 \%$ and $66.3 \%$, respectively. For activated carbon fibers, the proportions of $\mathrm{O}-\mathrm{C}=\mathrm{O}, \mathrm{C}-\mathrm{O}$ and $\mathrm{C}-\mathrm{C}$ are $19.8 \%, 32.7 \%$ and $47.5 \%$, respectively. Evidently, the proportion of oxygen-containing functional groups increases sharply after $\mathrm{KOH}$ activation.
The O1s XPS spectra of the two samples (Fig. 3c and d) also exhibited three main peaks with binding energies of around 535, 533.5 and $531.5 \mathrm{eV}$, which correspond to the functional groups of $\mathrm{C}-\mathrm{O}, \mathrm{C}=\mathrm{O}$ and $\mathrm{O}-\mathrm{C}=\mathrm{O}$, respectively ${ }^{30}$ For carbonized coconut fibers, the proportions of $\mathrm{C}-\mathrm{O}, \mathrm{C}=\mathrm{O}$ and $\mathrm{O}-\mathrm{C}=\mathrm{O}$ are $10.0 \%$, $41.5 \%$ and $48.5 \%$, respectively. For activated carbon fibers, the proportions of $\mathrm{O}-\mathrm{C}=\mathrm{O}, \mathrm{C}-\mathrm{O}$ and $\mathrm{C}-\mathrm{C}$ are $17.8 \%, 46.9 \%$ and $35.2 \%$, respectively. The results also prove that chemical activation can result in increased oxygen content of the carbon material.
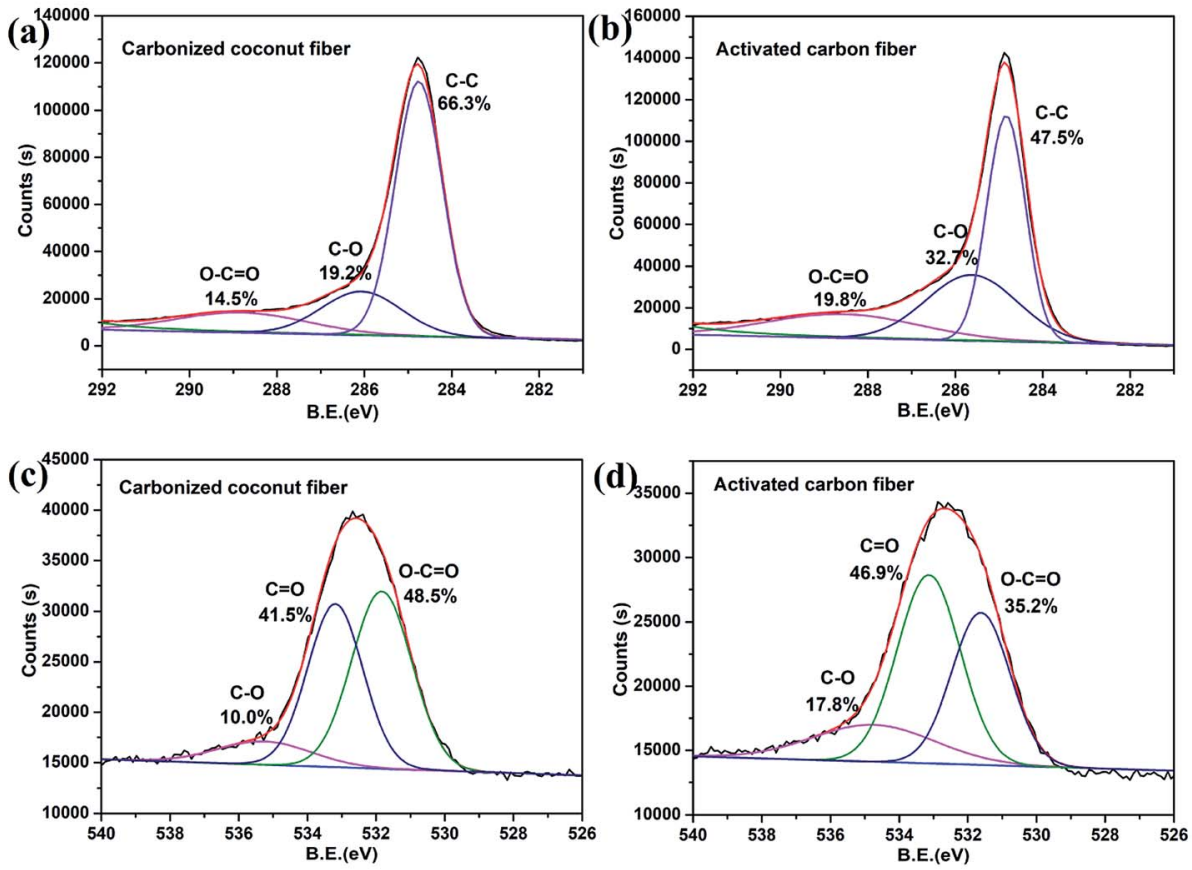

Fig. 3 XPS diagram about C1S and O1S of carbonized coconut fibers and activated carbon fibers. (a) and (b) are the C1s XPS spectra of the two samples. (c) and (d) are the O1s XPS spectra of the two samples. 
Table 1 BET specific surface area and pore texture of the as-prepared activated carbon fiber

\begin{tabular}{lll}
\hline Parameter name & $\begin{array}{l}\text { Parameter } \\
\text { value }\end{array}$ & $\begin{array}{l}\text { Parametric } \\
\text { unit }\end{array}$ \\
\hline $\begin{array}{ll}\text { BET total specific surface area } \\
\text { Micropore internal surface area }\end{array}$ & 1556 & $\mathrm{~m}^{2} \mathrm{~g}^{-1}$ \\
Micropore internal percentage & 78.5 & $\mathrm{~m}^{2} \mathrm{~g}^{-1}$ \\
Micropore external surface area & 335 & $\mathrm{~m}^{2} \mathrm{~g}^{-1}$ \\
Micropore external percentage & 21.5 & $\%$ \\
Langmuir specific surface area & 1715 & $\mathrm{~m}^{2} \mathrm{~g}^{-1}$ \\
Total pore volume of adsorption & 0.72 & $\mathrm{~cm}^{3} \mathrm{~g}^{-1}$ \\
Micropore volume & 0.49 & $\mathrm{~cm}^{3} \mathrm{~g}^{-1}$ \\
Micropore volume percentage & 68.0 & $\%$ \\
External pore volume & 0.23 & $\begin{array}{l}\% \\
\text { External pore percentage }\end{array}$ \\
Average pore size of adsorption & 32 & $\mathrm{~nm}^{-1}$ \\
\hline
\end{tabular}

\subsection{Analysis of specific surface area and pore characteristics}

The specific surface area and pore structures of activated carbon are the key factors to determine its adsorption capacity, and it is often used as an important indicator to characterize the adsorption performance of activated carbon. The parameters of specific surface area and pore structure of the as-prepared activated carbon fiber are listed in Table 1. Nitrogen adsorption-desorption isotherms of activated carbon fiber are shown in Fig. 4. The pore volume of the pore size distribution curve in the HK method is shown in Fig. 5, and the BJH analysis curve of mesoporous pore volume and size distribution is shown in Fig. 6. As can be seen from Table 1, the specific surface area of activated carbon fiber was $1556 \mathrm{~m}^{2} \mathrm{~g}^{-1}$, and the pore volume was $0.72 \mathrm{~cm}^{3} \mathrm{~g}^{-1}$. The specific surface area of activated carbon is larger, leading to better adsorption performance. Through the analysis of the relevant parameters, it can be observed that the micropore surface area of activated carbon fiber accounted for $78.5 \%$ of the total surface area, and that the pore volume of micropores accounted for $68 \%$ of the total pore volume. That is, most of the surface area and pore volume of the activated carbon fiber are attributed to the micropores (diameter less than $2 \mathrm{~nm}$ ). The results indicated that the activated carbon fibers prepared by this method had dominant micropores, which affords an advantage in the adsorption of small molecules. ${ }^{31}$ Fig. 4 shows the plot of relative pressure $\mathrm{P} / \mathrm{P}_{0}$ and adsorbed gas volume. The specific surface areas of coconut fiber and activated carbon fiber are $20.5 \mathrm{~m}^{2} \mathrm{~g}^{-1}$ and $1556 \mathrm{~m}^{2} \mathrm{~g}^{-1}$, respectively. The results indicate that the specific surface area of the activated carbon fiber was significantly increased after carbonization and $\mathrm{KOH}$ activation compared with that of the coconut fiber. Fig. 4 shows the $\mathrm{N}_{2}$ adsorption-desorption isotherm of the as-prepared activated carbon fibers. When the relative pressure $P / P_{0}$ is less than 0.04 , the isotherm rises very quickly, whereas, when $P / P_{0}$ is between $0.04-0.2$, the isotherm slope becomes smaller and there is no significant turning point and platform. It is noteworthy that, at a relative pressure of 0.5 , there is a faintly visible hysteresis loop. According to the classification standard of IUPAC, ${ }^{32}$ the adsorption-desorption isotherms of the activated carbon fibers belong to types I and IV, which indicates that the product is rich in micropores and contains a certain amount of mesopores. In the adsorption process, monolayer adsorption onto micropores plays a decisive role at lower relative pressure region. At higher relative pressure region, multilayer adsorption occurred on activated carbon, where the nitrogen capillary condensation took place in the mesopores, and thus, the mesopores also play an important role in the adsorption of nitrogen. ${ }^{33}$ From the distribution curve of micropores and mesopores shown in Fig. 5 and 6, it can be observed that the inside of the activated carbon fibers are

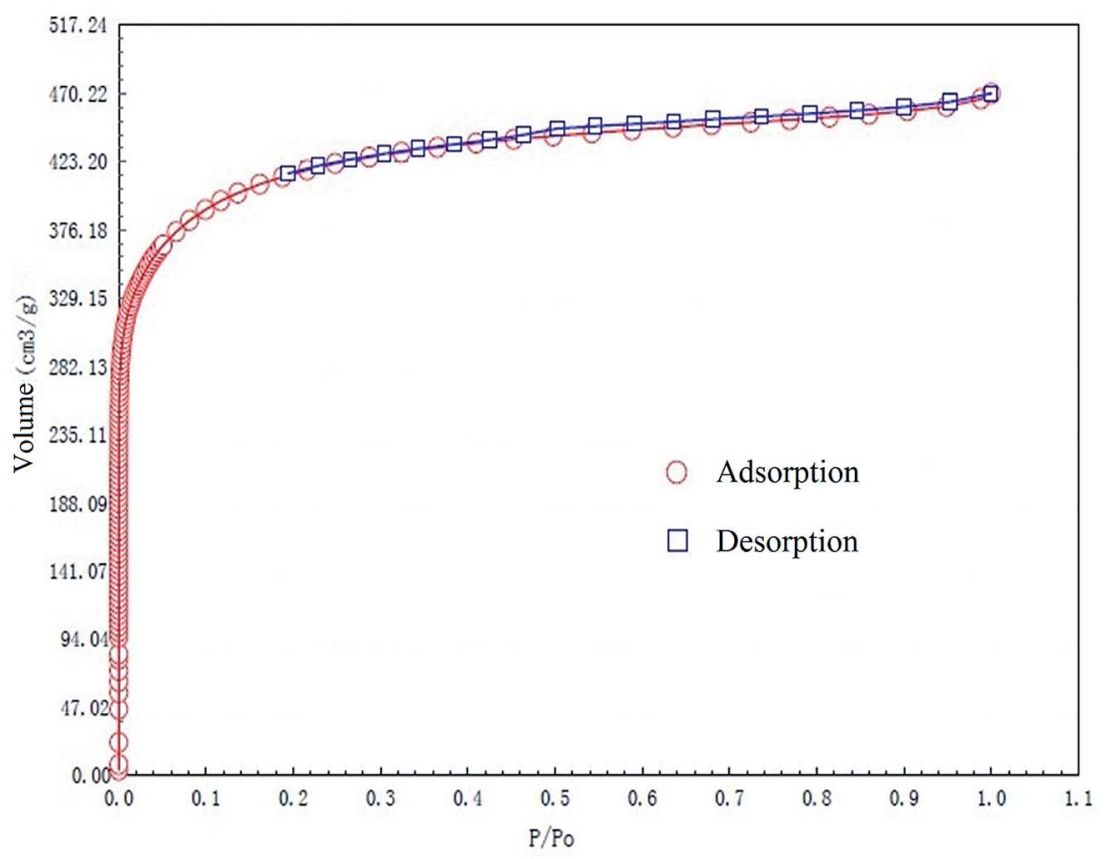

Fig. $4 \quad \mathrm{~N}_{2}$ adsorption/desorption isotherms of the as-prepared activated carbon fibers. 


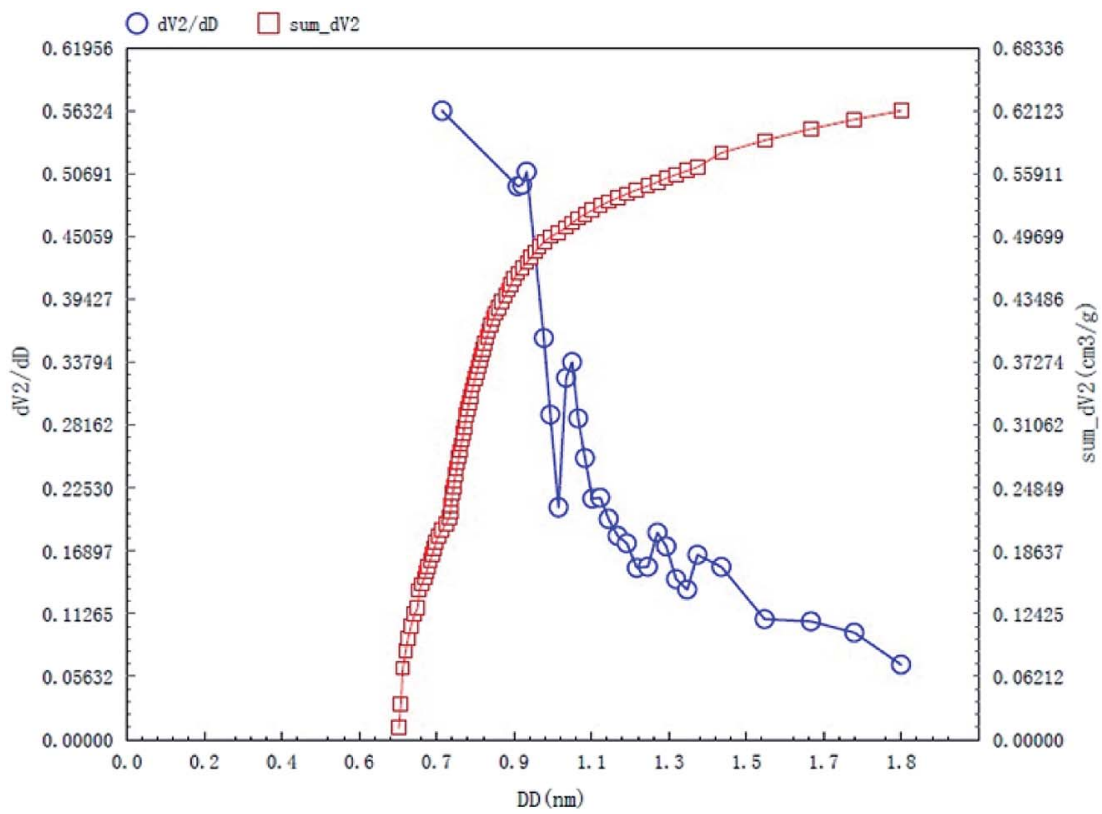

Fig. $5 \mathrm{HK}$ micropore distribution curves of the as-prepared activated carbon fibers.

mainly composed of micropores, which are mainly distributed in the range of $0.7-1.8 \mathrm{~nm}$. The size of mesopores is mainly distributed in the range of $2-9 \mathrm{~nm}$.

\subsection{Thermogravimetric analysis of coconut fibers}

Fig. 7 shows the thermal gravimetric analysis (TGA) and the derivative thermogravimetric analysis (DTGA) curves of the coconut fiber from 25 to $1100{ }^{\circ} \mathrm{C}$ at a heating rate of $10 \mathrm{~K} \mathrm{~min}^{-1}$. Throughout the TGA and DTGA curves, the heating pyrolysis process can be divided into three stages, that is, water evaporation stage, devolatilization and combustion stage, and decomposition stage. The details of three stages are discussed as follows: (i) at the first stage, within the temperature range of $25-200{ }^{\circ} \mathrm{C}$, a small weight loss of $8.7 \%$ was noted in the TGA curve, which is due to the evaporation of water in the sample. (ii) As the temperature increases from 200 to $360{ }^{\circ} \mathrm{C}$, the reaction goes to the second stage. The volatile components of the coconut fibers were evaporated out, and hence, the sample weight loss reached $41.2 \%$. A mass loss peak is located at $307^{\circ} \mathrm{C}$ and the biggest mass change rate of $-4.7 \%$ per min was observed at this temperature range. (iii) In the third stage of the reaction, the temperature continues to rise, the mass loss rate is $47.8 \%$ in the temperature range of $360-480^{\circ} \mathrm{C}$. The maximum mass loss peak is located at $434{ }^{\circ} \mathrm{C}$, corresponding to a mass

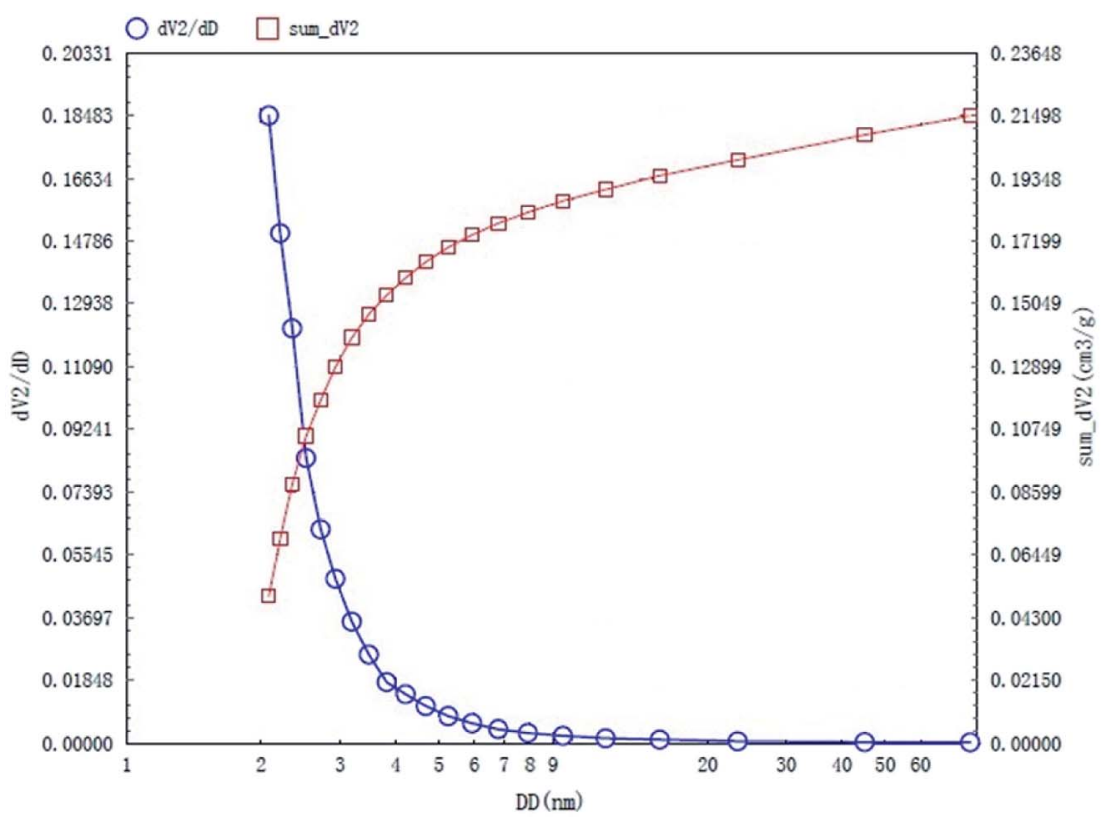

Fig. $6 \mathrm{BJH}$ mesopore distribution curves of the as-prepared activated carbon fibers. 


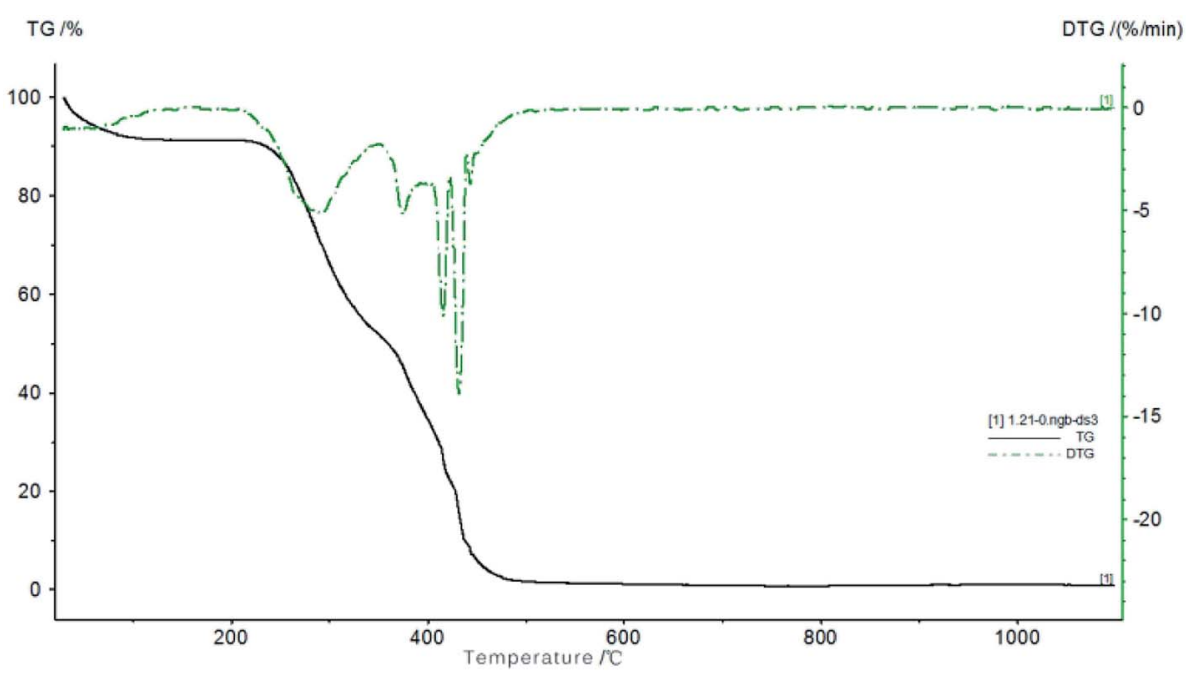

Fig. 7 TG/DTG curves of coconut fibers.

change rate of $-30.3 \%$ per min. There are three smaller peaks at this stage. The mass loss at this stage is mainly caused by the decomposition of organics, which accounts for a large proportion of the pyrolysis of fixed carbon. From 480 to $1100{ }^{\circ} \mathrm{C}$, the mass did not change significantly, indicating that the pyrolysis of fixed carbon is almost complete. Based on the above analysis, most of the organics in coconut fiber were burnt when the temperature reached $480{ }^{\circ} \mathrm{C}$, and the carbonization is completed at $600{ }^{\circ} \mathrm{C}$. Thus, the carbonization temperature of coconut fibers was selected to be $600{ }^{\circ} \mathrm{C}$.

\subsection{Fourier transform infrared (FTIR) spectroscopic analysis}

The chemical structure and functional groups of activated carbon fibers can be determined by Fourier transform infrared (FTIR) spectroscopy. The FTIR spectra of the coconut carbon fibers before and after the activation are shown in Fig. 8. From Fig. 8, we can see that the characteristic absorption peaks of carbonized coconut fiber and activated carbon fiber both

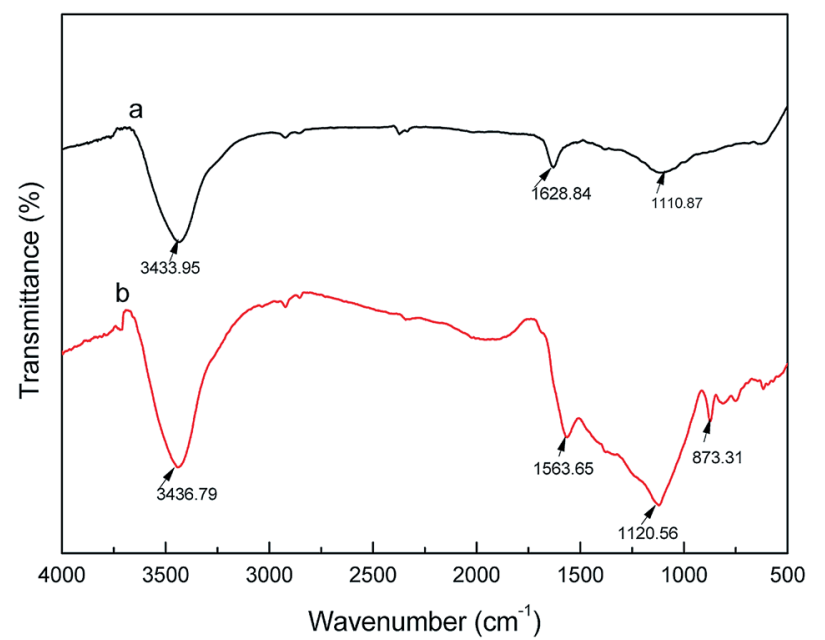

Fig. 8 FTIR spectra of carbonized (a) coconut fibers and (b) activated carbon fibers. appeared at 3435, 2920, 2850, 1610 and $1115 \mathrm{~cm}^{-1}$. The absorption peak at $3435 \mathrm{~cm}^{-1}$ was assigned to the $\mathrm{O}-\mathrm{H}$ bond stretching vibration, while those of $2920 \mathrm{~cm}^{-1}$ and $2850 \mathrm{~cm}^{-1}$ were assigned to the $\mathrm{C}-\mathrm{H}$ bond stretching vibrations. ${ }^{34}$ The $\mathrm{C}=\mathrm{C}$ bond stretching vibration in the aromatic ring resulted in an absorption peak at $1610 \mathrm{~cm}^{-1}$, and the absorption peak at $1115 \mathrm{~cm}^{-1}$ was attributed to the stretching vibration of the $\mathrm{C}-\mathrm{O}$ bond. In addition, the FTIR spectrum of the activated carbon fibers has a weak absorption peak at $873 \mathrm{~cm}^{-1}$, which is attributed to the bending vibration of the $\mathrm{C}-\mathrm{H}$ bond in the high degree of substitution of the aromatic ring. ${ }^{35}$ The results indicated that the carbonization of coconut fibers formed the aromatic ring after activation of $\mathrm{KOH}$, and that the hydrogen content in the aromatic ring was replaced by other substituents due to the activation temperature of $900{ }^{\circ} \mathrm{C}$. This is similar to the FTIR spectrum of activated carbon that was prepared from styrene-divinylbenzene at $1000{ }^{\circ} \mathrm{C}$ by phosphoric acid activation. ${ }^{34}$ Overall, the carbonized coconut fibers may contain hydroxyls, $-\mathrm{CH}_{2}-$ or $-\mathrm{CH}_{3}, \mathrm{C}=\mathrm{C}, \mathrm{C}-\mathrm{O}$ and other chemical groups, and the activated carbon fiber after activation of $\mathrm{KOH}$ may contain hydroxyl, $-\mathrm{CH}_{2}-$ or $-\mathrm{CH}_{3}, \mathrm{C}=\mathrm{C}, \mathrm{C}-\mathrm{O}$ and a higher degree of substituted aromatic ring and other chemical groups.

\subsection{Adsorption results}

The maximum absorption wavelength of methylene blue, Congo red and neutral red aqueous solution was located at 660, 500 and $520 \mathrm{~nm}$, respectively. A series of methylene blue, Congo red and neutral red aqueous solutions were prepared with different concentrations to determine the concentrationabsorbance curve of each dye in the corresponding maximum wavelength, and the standard curve equations and the fitting results are shown in Table 2.

The effects of initial dye concentration on the adsorption capacity and adsorption rate are shown in Fig. 9. It can be observed that the dye adsorption capacity and adsorption rate of the activated carbon fiber increase with the increasing initial concentration in $120 \mathrm{~min}$. The adsorption on the activated carbon fiber does 
Table 2 Fitting parameters of the three dyes

\begin{tabular}{lll}
\hline Dye name & Fitting curve & $\begin{array}{l}\text { Correlation } \\
\text { coefficient } R^{2}\end{array}$ \\
\hline Methylene blue & $A=0.1683 C+0.0065$ & 0.9992 \\
Congo red & $A=0.0078 C+0.0096$ & 0.9993 \\
Neutral red & $A=0.1003 C-0.0478$ & 0.9992
\end{tabular}

not reach equilibrium and the adsorption capacity was not saturated when the initial dye concentration was $5 \mathrm{mg} \mathrm{L}^{-1}$ in $120 \mathrm{~min}$. However, it can be observed from the adsorption rate curve that the adsorption rate of methylene blue and neutral red began to slow. If conditions do not change, the initial concentration continue to increase from $5 \mathrm{mg} \mathrm{L}^{-1}$, the sample of methylene blue and neutral red adsorption reached saturation at a certain concentration range, while the adsorption amount of Congo red is still increasing. In addition, when the initial solution concentration, $\mathrm{pH}$ and adsorption time of dyes were the same, we found that the adsorption capacity of methylene blue on activated carbon fiber reached the maximum. Comparing the three kinds of dyes, the adsorption rate of methylene blue is significantly greater than
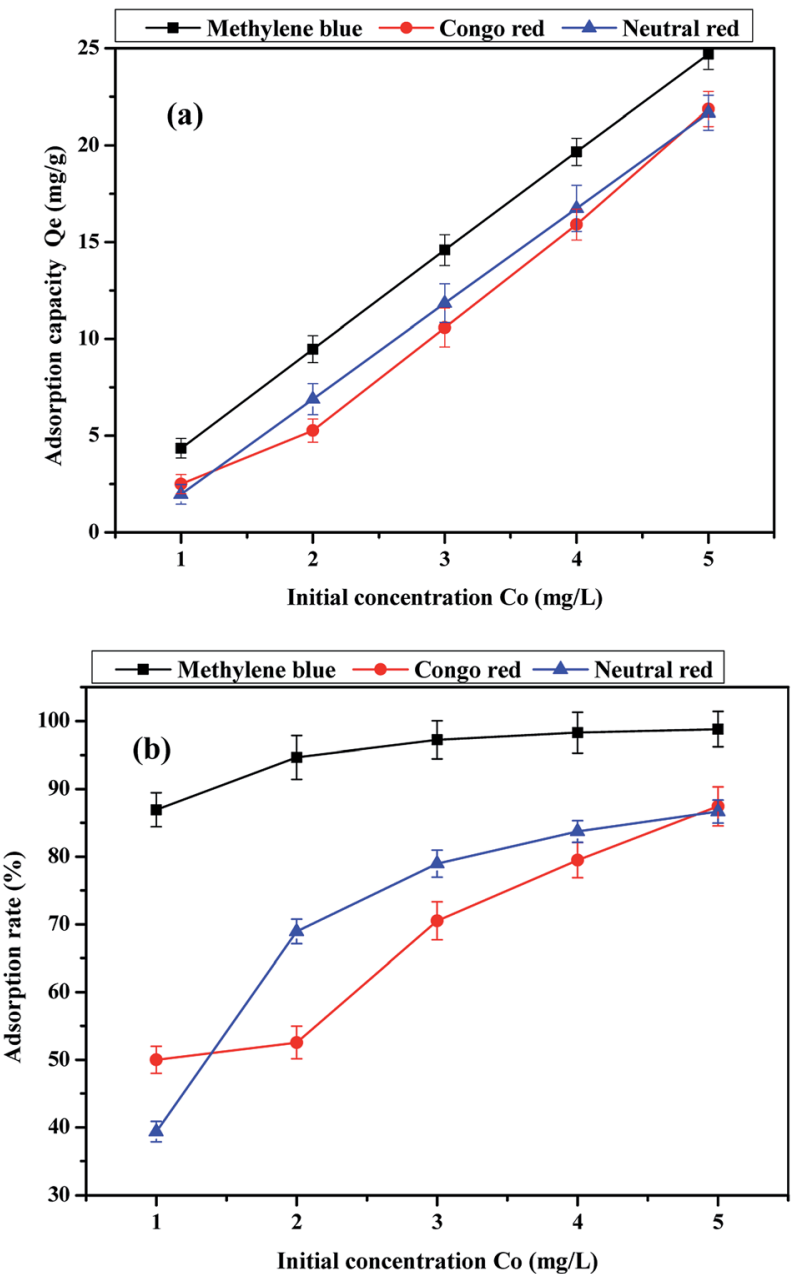

Fig. 9 Effect of initial concentration of the dye on (a) adsorption capacity and (b) adsorption rate. those of the other two kinds of dyes, and the difference is evident when the initial concentration is $1 \mathrm{mg} \mathrm{L}^{-1}$.

Usually, the colored ions of the basic dye are cations when the dye molecules are ionized in aqueous solution, and the acid dyes are vice versa (anions). At the same time, methylene blue, Congo red, and neutral red were basic dye, acid dye and less basic dye, respectively. At low $\mathrm{pH}$, coconut fiber-based activated carbon materials mainly have positive charge on their surface, which shows electrostatic repulsion towards methylene blue (cations) and neutral red (cations), while electrostatic adsorption towards Congo red dye (anions). The increase in pH leads to the positive charge of the activated carbon being gradually transformed to the negative charge. In this case, the electrostatic adsorption of activated carbon and Congo red is turned to repulsion, and there is an electrostatic attraction between methylene blue and neutral red. It is reported in some other research that there are two kinds of interaction forces between the activated carbon adsorbent and the compounds containing benzene ring (methylene blue, Congo red and neutral red all contain benzene rings) besides electrostatic adsorption. One is caused by the $\pi-\mathrm{H}$ bond between the hydrogen bond donor on the surface of activated carbon and the aromatic ring in the dyes, while the other is the $\pi-\pi$ dispersion force between the base surface of the activated carbon and the benzene ring. In this study, we speculated that these three forces existed in the adsorption process between coconut-activated carbon fibers and the three dyes. ${ }^{36-38}$ Fig. 10 shows the effect of $\mathrm{pH}$ on the adsorption capacity of the three kinds of dye aqueous solution. It can be observed that the effect of $\mathrm{pH}$ on the adsorption capacity is evident. On the basic dyes of methylene blue and neutral red, the amount of adsorption increased with the increase in $\mathrm{pH}$, the adsorption capacity reached the maximum when $\mathrm{pH}=9$. For acid dye of Congo red, the adsorption of Congo red dye on the activated carbon fiber is the largest at $\mathrm{pH}$ $=3$, and then with the increase in $\mathrm{pH}$, the adsorption capacity decreases. Therefore, the best $\mathrm{pH}$ for the adsorption of methylene blue and neutral red by activated carbon fiber was 9 , and the best $\mathrm{pH}$ for the adsorption of Congo red was 3 .

The effect of adsorption time on the adsorption capacity of the three dyes is shown in Fig. 11. The adsorption capacity of the activated carbon fibers to the three kinds of dyes increased with the extension of adsorption time. The adsorption capacity increased rapidly in the first 20 minutes and the adsorption tended to balance gradually in the latter stage. The adsorption capacities of methylene blue, Congo red and neutral red reached equilibrium at 150,120 , and $120 \mathrm{~min}$, respectively. It is mainly due to a large number of active adsorption sites on coconut-based activated carbon fibers. The early adsorption rate was faster because of the sufficient active sites and the later adsorption rate decreased to equilibrium because of the decrease in active sites. Since the adsorption occurred mainly on the surface of the activated carbon, when a certain amount of dye is adsorbed, the effect of steric hindrance slows down the adsorption rate of the dyes on the activated carbon. In addition, if the molecular weight of the dye increased, the adsorption and the saturated adsorption value of dyes reduce, with the dosage of adsorbent being constant. 


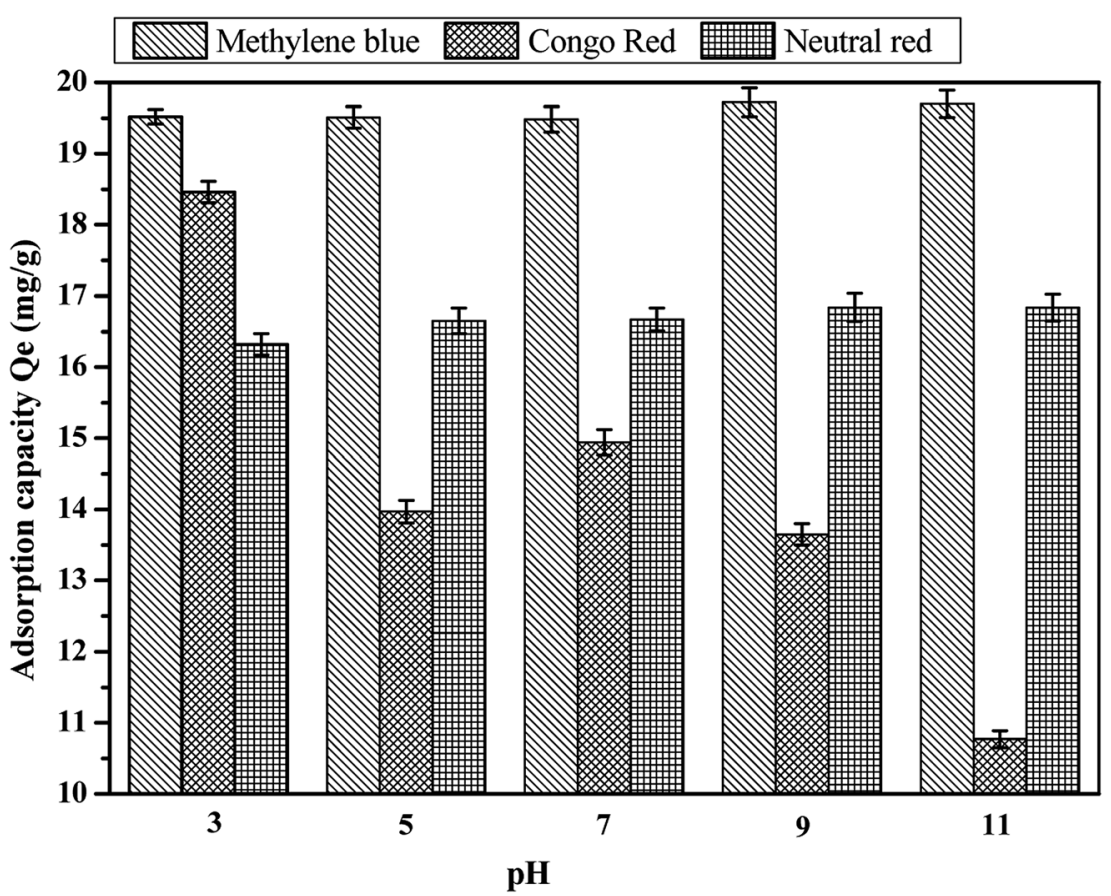

Fig. 10 Effect of pH on the adsorption capacity: (a) methylene blue, (b) Congo red and (c) neutral red.

Adsorption kinetic models are often used to describe laws of adsorption. The adsorption kinetics of coconut-based activated carbon fibers was studied based on the above adsorption equilibrium results of methylene blue, Congo red and neutral red dyes. By plotting a graph of processing time $T(\min ) v s . \ln \left(Q_{\mathrm{e}}\right.$ $-Q_{t}$ ), the first-order kinetic equation fitting curves can be obtained as shown in Fig. 12. By plotting a graph of processing time $T$ ( $\mathrm{min}) v s$. $t / Q_{t}$, the quasi-second-order kinetic equation fitting curves can be obtained as shown Fig. 13. By plotting the graph of $t^{1 / 2} v s$. $Q_{t}$, the fitting curve of particle diffusion equation can be obtained as shown in Fig. 14. According to the formulas given above, the calculated kinetic parameters are summarized in Table 3.
The adsorption equilibrium of methylene blue, Congo red and neutral red dye measured from experiment was 21.3, 22.1 and $20.7 \mathrm{mg} \mathrm{g}^{-1}$, respectively. By comparing the theoretical average adsorption amount of $Q_{\mathrm{e}}$ and the correlation coefficient of the fitting curve $R^{2}$ from Table 3 , we can see that, under the same condition, relative to the quasi-first-order kinetic equation and intraparticle diffusion model, quasisecond-level dynamic adsorption model is more accurate to describe the dynamic adsorption process of activated carbon fibers for methylene blue, Congo red, and neutral red, in which the corresponding quasi-second-order kinetic equations are $t / Q_{t}=0.1+t / 21.3, t / Q_{t}=0.11+t / 21.59$ and $t / Q_{t}=0.02$ $+t / 20.66$, respectively. The correlation coefficient of the quasi-

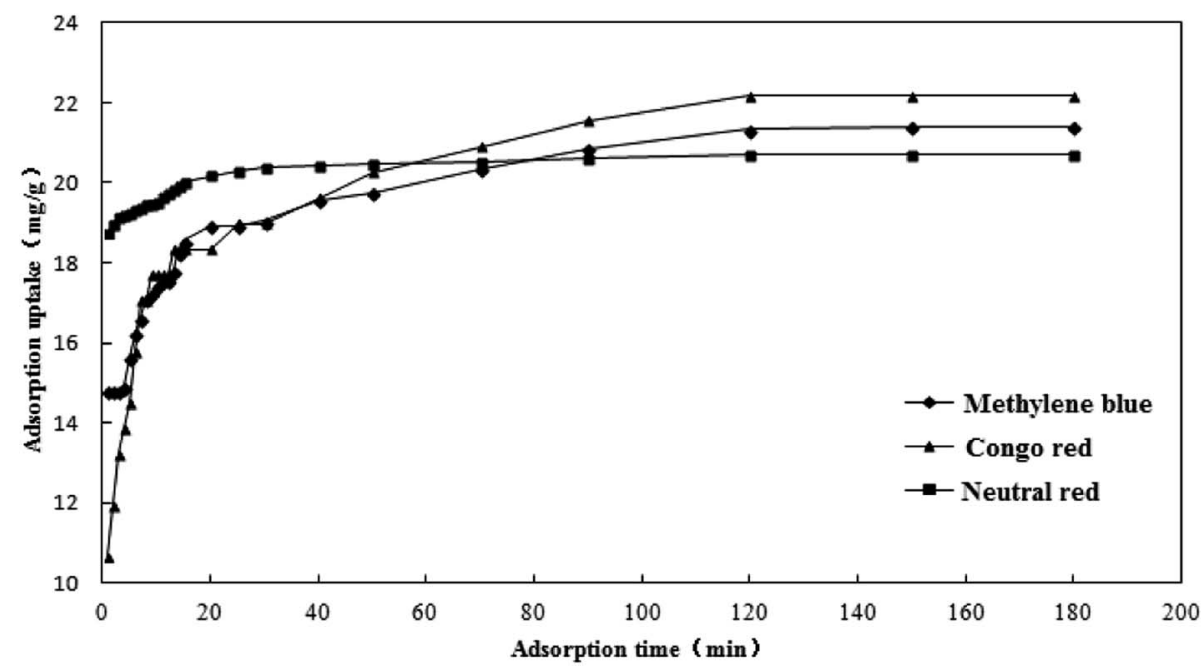

Fig. 11 Effect of adsorption time on the adsorption capacity. 

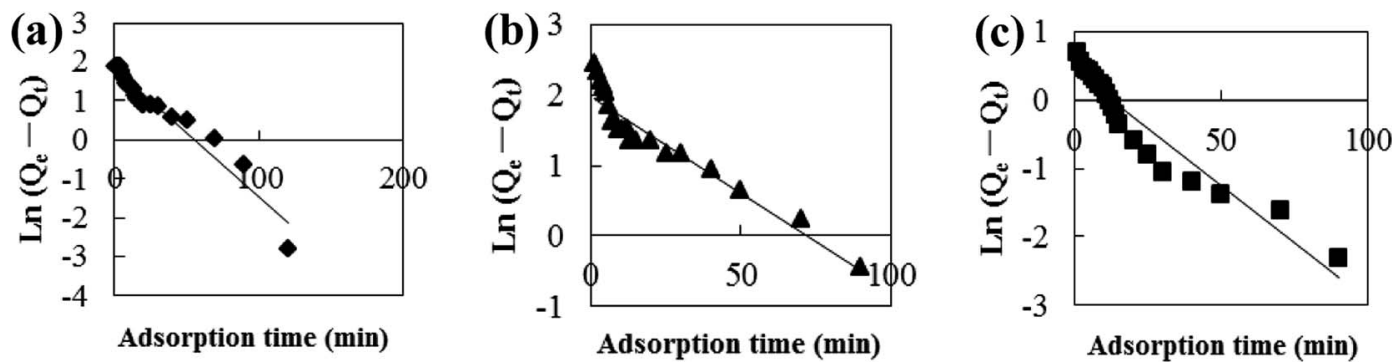

Fig. 12 Fitting curve of pseudo-first-order equation: (a) methylene blue, (b) Congo red and (c) neutral red.
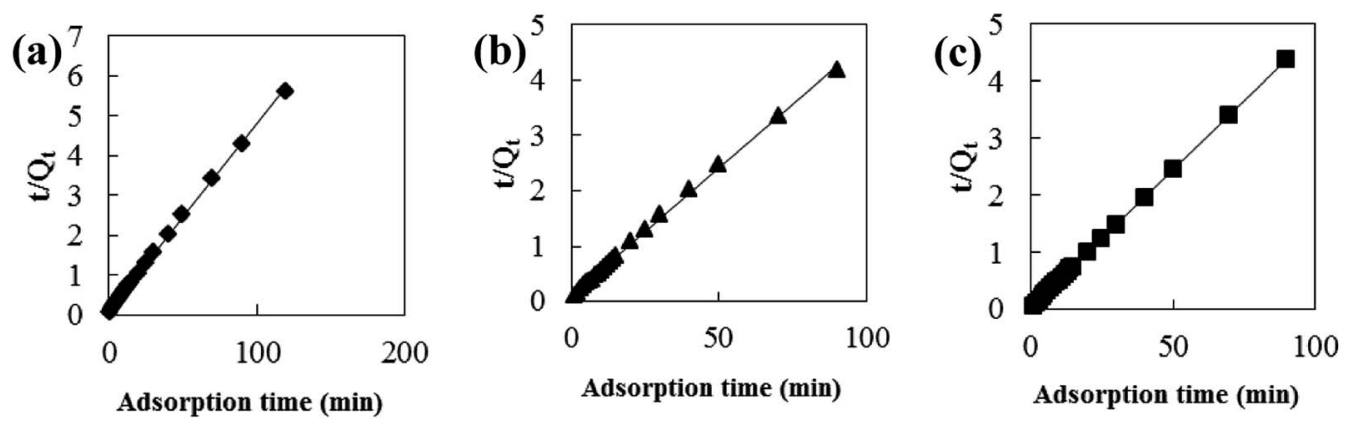

Fig. 13 Fitting curve of pseudo-second-order equation: (a) methylene blue, (b) Congo red and (c) neutral red.
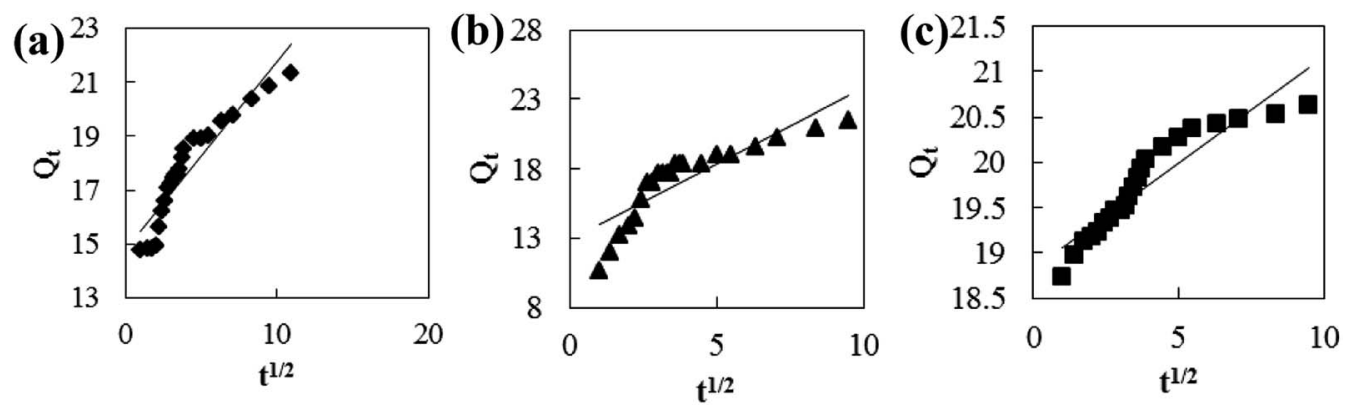

Fig. 14 Fitting curve of intraparticle diffusion equation: (a) methylene blue, (b) Congo red and (c) neutral red.

Table 3 Kinetic parameters of the adsorption of dye from activated carbon fiber

\begin{tabular}{|c|c|c|c|c|c|c|c|c|c|}
\hline \multirow[b]{2}{*}{ Dyestuff } & \multicolumn{3}{|c|}{ Pseudo first order kinetic model } & \multicolumn{3}{|c|}{ Pseudo-second-order kinetic model } & \multicolumn{3}{|c|}{ Particle diffusion model } \\
\hline & $K_{1}$ & $R_{1}{ }^{2}$ & $Q_{\mathrm{e}}$ & $K_{2}$ & $R_{2}{ }^{2}$ & $Q_{\mathrm{e}}$ & $K_{3}$ & $R_{3}{ }^{2}$ & Intercept \\
\hline Methylene blue & 0.0328 & 0.9377 & 6.1503 & 0.0214 & 0.9990 & 21.3220 & 0.6991 & 0.8684 & 14.774 \\
\hline Congo red & 0.0274 & 0.8903 & 7.2420 & 0.0190 & 0.9985 & 21.5982 & 1.1002 & 0.7481 & 12.863 \\
\hline Neutral red & 0.0335 & 0.9174 & 1.5148 & 0.1116 & 0.9999 & 20.6612 & 0.2323 & 0.8663 & 18.831 \\
\hline
\end{tabular}

second-stage kinetic equation of neutral red is 0.9999 , which showed that conformity degree of adsorption process of activated carbon fiber on neutral red was higher. In addition, the intercept of diffusion equation of neutral red particles was larger, which shows that the adsorption effect on the inner surface was larger. However, the linear fitting of the three dyes to $Q_{t}-t^{1 / 2}$ was low, and thus, it shows that the particle diffusion process on activated carbon fiber is not the adsorption rate control step for methylene blue, Congo red and neutral red. The results indicate that complexation, coordination or chelation may occur between the adsorbent and the adsorbate via covalent or electronic exchange, belonging to the 
chemical adsorption process, and revealing the inherent regularity of adsorption of activated carbon fibers.

\section{Conclusions}

Activated carbon fibers were prepared using coconut palm fibers as a precursor. It was found that the activation process could effectively increase the specific surface area of carbon materials by forming numerous micro pores and inhibiting the formation and precipitation of tar on the surface of carbon fibers. The specific surface area of the resulting activated carbon fibers was $1556 \mathrm{~m}^{2} \mathrm{~g}^{-1}$ and the pore volume reached $0.72 \mathrm{~cm}^{3}$ $\mathrm{g}^{-1}$. The pore sizes of the activated carbon fibers are mainly distributed in the range of $0.7-1.8 \mathrm{~nm}$, and a few mesopores in the range of 2-9 $\mathrm{nm}$ are also present. Using methylene blue, Congo red, and neutral red as model pollutants, the adsorption capacities and adsorption rate of the resulting activated carbon fibers increased with the increasing initial dye concentration. Under the same conditions, the adsorption capacity and adsorption rate of methylene blue are the largest as compared with those of Congo red and neutral red. For the adsorption of methylene blue and neutral red, the adsorption capacity increased with the increasing $\mathrm{pH}$. For the adsorption of Congo red, the adsorption capacity showed a decreasing trend with the increasing $\mathrm{pH}$ value, and the adsorption capacity reached the maximum when the $\mathrm{pH}$ value was 3 . The optimal $\mathrm{pH}$ values of methylene blue, Congo red and neutral red were 9, 3 and 9, respectively. The adsorption kinetics can be well described by the quasi-second-order reaction model.

\section{Conflicts of interest}

There are no conflicts to declare.

\section{Acknowledgements}

This study was financially supported by the Project of Technology Research Center for Lingnan Characteristic Fruits \& Vegetables Processing and Application Engineering of Guangdong Province (No. [2015]1487), the Project of Food Science Innovation Team of Guangdong Higher Education Institutes (2016KCXTD020). The message of the fund is: Guangdong University of Petrochemical Technology 2018 university-level cultivation project for college students' innovation and entrepreneurship (2018pyA041, 2018pyA045).

\section{References}

$1 \mathrm{X}$. H. Duan, C. Srinivasakannan, X. Wang, F. Wang and X. Y. Liu, J. Taiwan Inst. Chem. Eng., 2017, 70, 374-381.

2 H. K. Son, S. Sivakumar, M. J. Rood and B. J. Kim, J. Hazard. Mater., 2016, 301, 27-34.

3 H. J. Amezquita-Garcia, J. R. Rangel-Mendez, F. J. Cervantes and E. Razo-Flores, Chem. Eng. J., 2016, 286, 208-215.

4 K. Xie, K. Zhang, Y. Han, K. Yuan, Q. Song, J. G. Wang and B. Wei, Electrochim. Acta, 2016, 210, 415-421.
5 X. Wang, Q. Guo and T. Kong, Chem. Eng. J., 2015, 273, 472480.

6 W. Xiao, Z. Wang, C. Miao and X. Yan, Electrochim. Acta, 2016, 216, 467-474.

7 Z. Wang, Y. Han, Y. Zeng, Y. Qie, Y. Wang, D. Zheng and Y. Tong, J. Mater. Chem. A, 2016, 4, 5828-5833.

8 E. Frank, L. M. Steudle, D. Ingildeev, J. M. Spörl and M. R. Buchmeiser, Angew. Chem., Int. Ed., 2014, 53, 52625298.

9 Y. Huang, E. Ma and G. Zhao, RSC Adv., 2015, 5, 7028770296.

10 J. Li, D. H. Ng, P. Song, C. Kong, Y. Song and P. Yang, Biomass Bioenergy, 2015, 75, 189-200.

11 C. H. Kim and B. H. Kim, J. Power Sources, 2015, 274, 512520.

12 Y. Zhao, F. Fang, H. M. Xiao, Q. P. Feng, L. Y. Xiong and S. Y. Fu, Chem. Eng. J., 2015, 270, 528-534.

13 S. M. Hong, S. W. Choi, S. H. Kim and K. B. Lee, Carbon, 2016, 99, 354-360.

14 N. Díez, P. Álvarez, M. Granda, C. Blanco, R. Santamaría and R. Menéndez, Chem. Eng. J., 2015, 260, 463-468.

15 X. Ge, Z. Wu, Z. Wu, Y. Yan, G. Cravotto and B. C. Ye, J. Taiwan Inst. Chem. Eng., 2016, 64, 235-243.

16 M. A. Yahya, Z. Al-Qodah and C. Z. Ngah, Renewable Sustainable Energy Rev., 2015, 46, 218-235.

17 V. K. Gupta, P. J. M. Carrott, R. Singh, M. Chaudhary and S. Kushwaha, Bioresour. Technol., 2016, 216, 1066-1076.

18 A. Jain, R. Balasubramanian and M. P. Srinivasan, Chem. Eng. J., 2016, 283, 789-805.

19 H. Tounsadi, A. Khalidi, M. Abdennouri and N. Barka, J. Taiwan Inst. Chem. Eng., 2016, 59, 348-358.

20 M. G. Lomelí-Ramírez, S. G. Kestur, R. Manríquez-González, S. Iwakiri, G. B. Muniz and T. S. Flores-Sahagun, Carbohydr. Polym., 2014, 102, 576-583.

21 N. Sarkar, G. Sahoo, T. Khuntia, P. Priyadarsini, J. R. Mohanty and S. K. Swain, Polym. Compos., 2017, 38, 2852-2862.

22 P. Staroń, J. Chwastowski and M. Banach, J. Cleaner Prod., 2017, 149, 290-301.

23 S. S. Kumar, D. Duraibabu and K. Subramanian, Mater. Des., 2014, 59, 63-69.

24 C. L. Hwang, V. A. Tran, J. W. Hong and Y. C. Hsieh, Constr. Build. Mater., 2016, 127, 984-992.

25 C. N. Cordeiro, M. S. d Rocha, A. C. Faleiros and I. Koshun, J. Colloid Interface Sci., 2005, 286, 459-461.

26 N. Álvarez-Gutiérrez, M. V. Gil, F. Rubiera and C. Pevida, Chem. Eng. J., 2017, 307, 249-257.

27 R. Zhang and M. Y. Han, Carbon Tech., 1999, 101(3), 19-21.

28 N. Wei, N. Q. Zhao and W. Jia, J. Mater. Sci. Eng., 2003, 21, 777-780.

29 Z. Li, L. Zhang, B. Li, Z. Liu, Z. Liu, H. Wang and Q. Li, Chem. Eng. J., 2017, 313, 1242-1250.

30 Z. Li, X. Hu, D. Xiong, B. Li, H. Wang and Q. Li, Electrochim. Acta, 2016, 219, 339-349.

31 C. Shi, J. W. Feng, S. C. Peng and Z. H. Hu, Environ. Chem., 2013, 32, 394-401. 
32 F. Rouquerol, J. Rouquerol and K. Sing, Adsorption by powders and porous solids, Academic Press, London, 1999, p. 205.

33 A. M. Warhurst, G. D. Fowler, G. L. Mcconnachie and S. J. T. Pollard, Carbon, 1997, 35, 1039-1045.

34 A. M. Puziy, O. I. Poddubnaya, A. M-Alonso, F. Suárez-Garcıa and J. M. D. Tascón, Carbon, 2002, 40, 1493-1505.

35 Y. Q. Lu and Z. H. Deng, Practical infrared spectroscopy, Science Press, Beijing, 1989, p. 30.
36 X. X. Yang, H. M. Chen, X. M. Gao and F. Fu, Ion Exch. Adsorpt., 2018, 34, 247-258.

37 L. M. Cotoruelo, M. D. Marqués, F. J. Díaz, R. M. José, J. J. Rodríguez and C. Tomás, Chem. Eng. J., 2012, 184, 176-183.

38 Y. Y. Zhou, X. C. Liu, L. Tang, F. F. Zhang, G. M. Zeng, X. Q. Peng, L. Luo, Y. C. Deng and Y. Pang, J. Hazard. Mater., 2017, 333, 80-87. 